Energy Research Journal 2 (1): 17-21, 2011

ISSN 1949-0151

(C) 2011 Science Publications

\title{
Proposed Reliability Techniques on Soil and Rock Excavations
}

\author{
Tangchawal, S. \\ Geoscience Program, School of Science and Technology, \\ Mahidol University Kanchanaburi Campus, Thailand 71150, Thailand
}

\begin{abstract}
Problem statement: Assessment of the ground mass excavation is normally done by the deterministic method. A quantitative indication of mass stability provides as an index term known "the Factor of Safety (F.S.)". There are uncertain to some degrees, such as only a single value of mass properties is used or variation in geologic conditions, computed values of F.S. are never absolutely precise. An alternative measurement of stability regarding use of index terms "Reliability (R) and probability of failure [p (f)]" is to cope with the uncertainty well. Concurrent processes of stability assessment are done using both the deterministic and reliability methods. Field data on the reliability approach assumed to be either normal function or lognormal function distribution. Conclusion/Recommendations: Three types of reliability model are proposed. Modeling types are based on the safety margin, the most likely value of F.S. and data simulation, respectively. These probabilistic values obtained from each model, are compared with the deterministic method. The risk on ground mass failures and environmental impacts due to excavation, be better defined and also achieved the optimized cost of construction excavation.
\end{abstract}

Key words: Ground mass excavation, deterministic and reliability methods, risk of failure, reliability models, optimized excavation cost

\section{INTRODUCTION}

Soil or rock excavation at the construction site for slope or structure foundation is normally carried out by machinery, or in some cases using the explosives. Ground mass stability calculated by using the input data from filed or laboratory results. The deterministic method, applied for the calculation of stability index term known "the Factor of Safety (F.S.)". There are disadvantages of the deterministic method to some degrees, such as only a single value of mass properties is used or variations in geologic conditions at the cutting face. Hence, the computed values of F.S. are never precise. To gain better indication for the possibility chance of failure, the statistical analysis using the reliability method is suggested (Duncan, 2002; Tangchawal, 2008). Concurrent processes using both the deterministic and the reliability methods. Field data on the probabilistic approach assumed to be either normal or lognormal distribution. Application of the reliability method can lead to the values of Reliability (R) and probability of failure [(p (f)], in which they can compare with the value of Factor of Safety (F.S.). Three models of reliability methods are proposed by the author. Using of both deterministic and reliability methods, the stability and environmental impacts is better defined. The relevant cost of excavation is also optimized.
Stability planning: For the stability planning on cutting slope and foundation by using the machines or explosives, the material types are important factors. If the materials are mainly soil, the common types of failure are plane or circular failure. But if they are mainly rock, failure types are plane, wedge or toppling failure. The equations of Factor of Safety (F.S.) are set for each type of failure based on the limit equilibrium. For normal practice on slope and embankment cut, the value of F.S. $=1.3$ is actually accepted for short term mass stability and F.S. $=1.5$ is for long term mass stability.

Modeling for risk of mass failures: To find the chance of mass failures, three types of risk models are proposed by the researcher (Tangchawal, 2008). The first model is assigned to have calculation based on the safety margin value, while the second model based on the most likely value of factor of safety. The third model is the simulation model using the combined algorithms of generating random numbers, sampling, comparison of factor of safety and calculation for the failure chances. The risk values determined from the first and the second model are deterministic index values, but for the third model, the risk index value is probabilistic index from the repeat process of data simulation. Steps of calculation for the three models are briefly explained. 
Risk model based on the safety margin value: If there is a normal distribution among those input random variables (such as cohesion, friction angle) the empirical equations used the probabilistic method are implied. The probability of failure model for normal distribution data is then set as shown on Fig. 1. The relationship on the limit of safety between the capacity and demand value, called "safety margin (Z)". Harr (1987) defined as Eq. 1-2:

$\mathrm{Z}=\mathrm{R}-\mathrm{Q}$

(F.S.) $)_{\text {mean }}=\frac{\mathrm{R}_{\text {mean }}}{\mathrm{Q}_{\text {mean }}}$

Term (FS) $)_{\text {mean }}$ is the mean index value of stability estimation. The mean capacity $\left(\mathrm{R}_{\text {mean }}\right)$ value is to resist movement and the mean demand $\left(\mathrm{Q}_{\text {mean }}\right)$ value is to develop movement on the failure plane.

An alternative value is the reliability term (Duncan, 2000; Duncan and Wright, 2005; Harr, 1987). It is a value indicating the reliability of excavation and it is the computed probability that a slope or foundation will not fail and is equal to 1.0 minus the probability of failure, [p (f)]. The probabilistic relationship between the probability of failure and the cumulative distribution function, or $\mathrm{F}(\mathrm{x})$, while $\mathrm{x}$ is the assumed random variable (or in another term is the reliability index, $\beta$ ) as it is indicated in Equations 3-6:

Reliability $=1-p(f)$

$p(f)=1-F(x)=1-F(\beta)$

$\beta_{\mathrm{N}}=\frac{\left(\mathrm{R}_{\operatorname{man}}-\mathrm{Q}_{\text {man }}\right)}{\sqrt{\sigma_{\mathrm{R}}^{2}+\sigma_{\mathrm{Q}}^{2}}}$

Term $\beta_{\mathrm{N}}$ in Fig. 1 and of Eq. 5 is the reliability index for the normal distributed data, which is the value of number of standard deviation $(\sigma)$ between F.S. $=1$ (at $\mathrm{Z}=0$ ) and at $(\mathrm{Z})_{\text {mean }}$.

If there is a lognormal distribution among input random variables, the assumed variable $\mathrm{y}=\ell \mathrm{n} \mathrm{x}$ is normally distributed and their Coefficient Of Variation $(\mathrm{COV})$ values are indicated. The reliability index value for the lognormal, $\beta_{\mathrm{LN}}$ is:

$\beta_{\mathrm{LN}}=\frac{\ln \left\{\left(\frac{\bar{R}}{\bar{Q}}\right) \cdot \frac{\left[1+\left\{(\text { (C.O.V. })_{Q}^{2}\right\}\right]}{\left.\left[1+\left\{(\text { C.O.V. })_{R}^{2}\right\}\right]\right\}}\right.}{\sqrt{\ln \left\{\left[1+(\text { C.O.V. . })_{R}^{2}\right]\left[1+(\text { C.O.V. })_{Q}^{2}\right]\right\}}}$

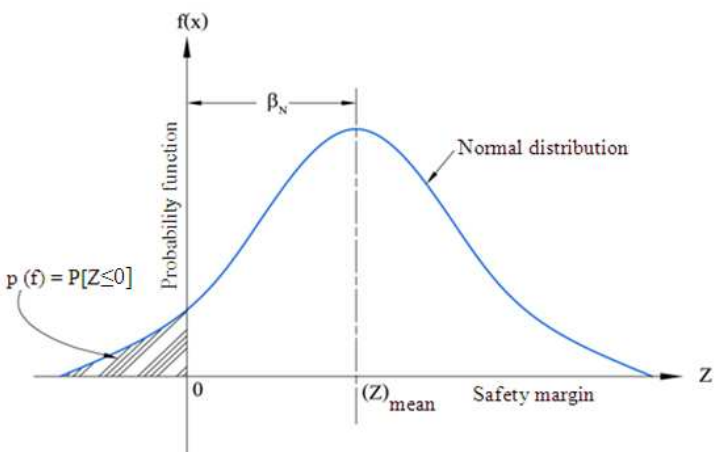

Fig. 1: The state of failure based on the safety margin value, failure occurs when $\mathrm{z} \leq 0$. This curve indicates the value of reliability index $\left(\beta_{\mathrm{N}}\right)$ for normal distribution data

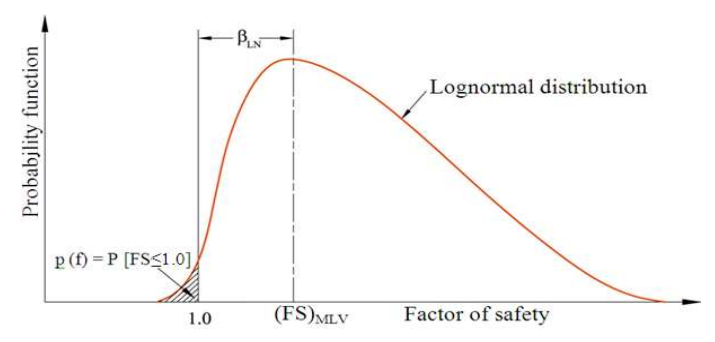

Fig. 2: The state of failure based on the most likely value of factor of safety, failure occurs when FS $\leq 1.0$. This curve indicates the value of reliability index $\left(\beta_{\mathrm{LN}}\right)$ for lognormal distribution data

\section{Risk model based on the probable value of factor of safety:}

- If there is a normal distribution among those input random variables, the reliability index, $\beta_{\mathrm{N}}$, which based on the most likely value of factor of safety, $(\mathrm{FS})_{\mathrm{MLV}}$ is Eq. 7:

$\beta_{\mathrm{N}}=\frac{\left[(\mathrm{F} . \mathrm{S} .)_{\mathrm{MLV}}-1\right]}{\sigma_{\mathrm{FS}}}$

- But if there is a lognormal distribution among those input random variables, $\beta_{\mathrm{LN}}$ (Fig. 2) is Eq. 8:

$\beta_{\mathrm{LN}}=\frac{\ln \left[\frac{(\mathrm{FS} .)_{\mathrm{MLV}}}{\sqrt{1+(\mathrm{C} . \mathrm{O} . \mathrm{V} .)_{\mathrm{FS}}^{2}}}\right]}{\sqrt{\ln \left[1+(\mathrm{C} . \mathrm{O} . \mathrm{V} .)_{\mathrm{FS}}^{2}\right]}}$

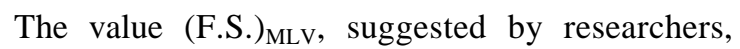
(Duncan, 2000; Duncan and Wright, 2005) is obtained 
by adding and subtracting the random variables for one standard deviation value Eq. 9:

$$
\text { (F.S. })_{\mathrm{MLV}}=\frac{\left(\mathrm{F}_{1}^{+}+\mathrm{F}_{1}^{-}\right)+\left(\mathrm{F}_{2}^{+}+\mathrm{F}_{2}^{-}\right)+\ldots+\left(\mathrm{F}_{\mathrm{N}}^{+}+\mathrm{F}_{\mathrm{N}}^{-}\right)}{2(\mathrm{~N})}
$$

Terms $\mathrm{F}_{1}^{+}, \mathrm{Fl}_{1}^{-}$are the adding $1 \mathrm{SD}$ and subtracting $1 \mathrm{SD}$ from the mean value of its first random variable. Similarly $\mathrm{F}_{2}^{+}, \mathrm{F}_{2}^{-}$are for the second variable, until $\mathrm{N}^{\text {th }}$ variable.

In order to find the new standard deviation value based on the factor of safety, the equation for $\sigma_{\mathrm{FS}}$ is given Eq. 10:

$\sigma_{\mathrm{FS}}=\sqrt{\left(\frac{\Delta \mathrm{F}_{1}}{2}\right)^{2}+\left(\frac{\Delta \mathrm{F}_{2}}{2}\right)^{2}+\ldots+\left(\frac{\Delta \mathrm{F}_{\mathrm{N}}}{2}\right)^{2}}$

Value of each $\Delta \mathrm{F}$ is defined as the absolute value of the difference between the adding and subtracting value of the factor of safety Eq. 11:

$$
\Delta \mathrm{F}_{1}=\left|\mathrm{F}_{1}^{+}-\mathrm{F}_{1}^{-}\right|
$$

Then the coefficient of variation based on the factor of safety is obtained Eq. 12:

$$
(\mathrm{COV})_{\mathrm{FS}}=\frac{\sigma_{\mathrm{FS}}}{(\mathrm{FS})_{\mathrm{MLV}}}
$$

Based on various published values (Duncan, 2000; Duncan and Wright, 2005; Harr, 1987), the researcher of this article suggests the value of coefficient of variation (C.O.V.) be within the range $15-40 \%$. The lowest conceivable value [(C.O.V. $\left.)_{\text {low }}\right]$ is $15 \%$ and the highest conceivable value [(C.O.V. $\left.)_{\text {high }}\right]$ is $40 \%$. These two values help during the computation process, when the data are not enough for statistical calculation.

Risk model based on the simulated data from random sampling: The Monte Carlo technique is used in the process to calculate the simulated value of probability of failure and the range of F.S. values. In the simulation process, it has generated random values between 1000-10000 times. The index value obtained from simulation is used to compare with the deterministic F.S. values obtained from the two previous models.

Random numbers between 0-1.0 are generated. Sampling the probability density function values between $-4(\mathrm{SD})$ and +4 (SD) and the calculated F.S. value.

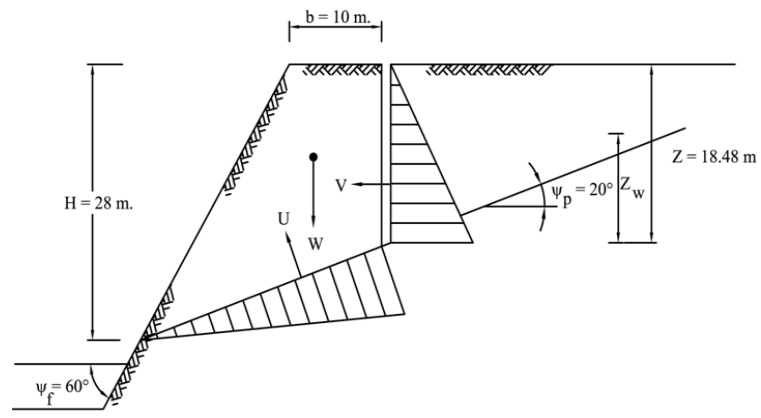

Fig. 3: A plane failure on the quarry limestone face which has the tension crack on the upper bench. $\mathrm{U}$ is the uplift force and $\mathrm{V}$ is the water force in the crack. $\mathrm{W}$ is the sliding weight, the maximum value of water height $\left(\mathrm{z}_{\mathrm{w}}\right)$ is $18.48 \mathrm{~m}$. Other dimensions indicate in this figure.

If the F.S. value is greater than 1.0, it is accepted as the output. But if the F.S. is less than 1.0, the random value is regenerated and the process is repeat for $\mathrm{L}$ times (default value at 1000 times). Then determine the probability of failure from a ratio:

$[\mathrm{p}(\mathrm{f})]_{\mathrm{SIM}}=\frac{(\mathrm{L}-\mathrm{M})}{\mathrm{L}}$

In Eq. 13, $M$ is the number of times the resisting force exceeded the displacing force. The index value of probability of failure obtained from the simulation process is called "the simulated $\mathrm{p}(\mathrm{f})$, or $\left[\mathrm{p}(\mathrm{f})_{\mathrm{SIM}}\right]$ ".

Back analyses using the proposed risk models: All writing source code and the use of spreadsheet program have been done. Example problems are shown for 2 cases.

Slope cut in massive limestone: The cross section in Fig. 3 shows the dimension, geometry and water forces. Failure occurred on bedding planes striking parallel to the face and dipping out of face at an angle of $20^{\circ}$. The quarry rock unit weight is $25.1 \mathrm{kN} \mathrm{m}^{-3}$. From the observation and laboratory results, the friction angle is $20^{\circ}$ and cohesion value is $100 \mathrm{kPa}$.

The deterministic value for the factor of safety on the slope is Eq. 14:

F.S. $=\frac{(\mathrm{cL})+\left[\left(\mathrm{W} \cos \psi_{\mathrm{p}}\right)-\mathrm{U}-\left(\mathrm{V} \sin \psi_{\mathrm{p}}\right)\right] \tan \varphi}{\left(\mathrm{W} \sin \psi_{\mathrm{p}}\right)+\left(\mathrm{V} \cos \psi_{\mathrm{p}}\right)}$

Assume that there are four random variables involved in the stability analysis. These are the friction angle $(\phi)$, the angle of failure plane $\left(\psi_{\mathrm{p}}\right)$, cohesion (c) and the rock unit weight $(\gamma)$. All random variables have the normal distribution of the data and their value of C.O.V. is the same at $15 \%$. 


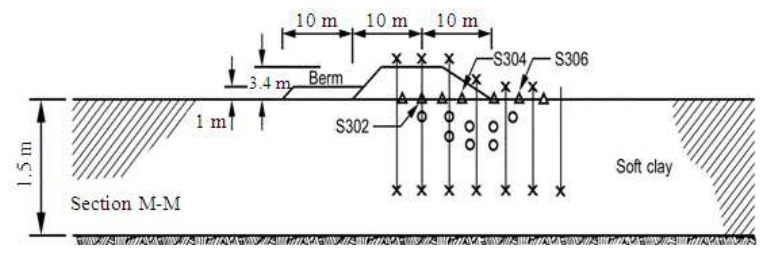

Fig. 4: Embankment test in 1975 by the staff of Asian Institute of Technology, Thailand (Bergado, 1994).

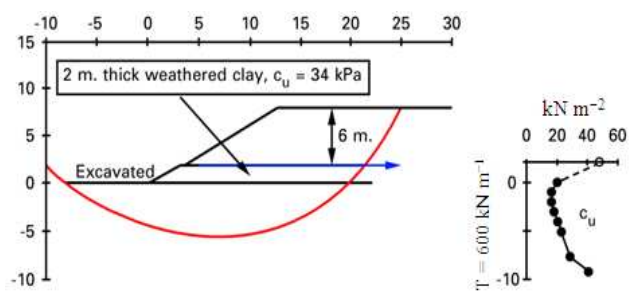

Fig. 5: Critical slip circle for the three layer geotextile reinforcement. The variation of undrained cohesion $\left(\mathrm{c}_{\mathrm{u}}\right)$ is indicated in a small graph.

Table 1: Calculation values for case 1 on slope stability

\begin{tabular}{ll}
\hline $\begin{array}{l}\text { RISK model I } \\
(\mathrm{FS})_{\text {mean }}=1.02\end{array}$ & $\mathrm{p}(\mathrm{f})_{\mathrm{I}}=45.5 \%$ \\
RISK model II & $\mathrm{p}(\mathrm{f})_{\mathrm{II}}=43.3 \%$ \\
$(\mathrm{FS})_{\mathrm{MLV}}=1.02$ & \\
RISK model III & {$[\mathrm{p}(\mathrm{f})]_{\mathrm{SIM}}=42.7 \%$} \\
$(\mathrm{FS})_{\text {range }}=0.66-1.45$ &
\end{tabular}

Table 2: Important properties of clay soil adapted for statistical calculation by the author

\begin{tabular}{|c|c|c|c|c|c|c|}
\hline Variable & & $\mathrm{x}$ value & Mea & & $\sigma$ & C.O.V \\
\hline Unit weig & $\left.\mathrm{N} \mathrm{m}^{-3}\right)$ & 19.200 & 19.2 & & 0.960 & 0.05 \\
\hline Cohesion, & $\left.\mathrm{N} \mathrm{m}^{-2}\right)$ & 16.000 & 16.0 & & 2.400 & 0.15 \\
\hline Friction an & $\phi_{\mathrm{m}}$ (degrees) & 30.000 & 30. & & 3.000 & 0.10 \\
\hline Reinforc & ion, $\mathrm{T}\left(\mathrm{kN} \mathrm{m}^{-1}\right)$ & 200.000 & 200.0 & & 20.000 & 0.10 \\
\hline Length, lev & $(\mathrm{m})$ & 15.915 & 15. & & 2.387 & 0.15 \\
\hline Critical hei & $\mathrm{H}(\mathrm{m})$ & 2.000 & 2.0 & 00 & 0.600 & 0.30 \\
\hline Depth (m) & $\mathrm{c}_{\mathrm{u}}\left(\mathrm{kN} \mathrm{m}^{-2}\right)$ & Mean $(\mathrm{kI}$ & $\left(\mathrm{m}^{-2}\right)$ & & $\mathrm{kN} \mathrm{m}^{-2}$ ) & C.O.V \\
\hline$\overline{0}$ & 20.0 & 20.0 & & 3.0 & & 0.15 \\
\hline 1 & 16 & 16.0 & & 2. & & 0.15 \\
\hline 2 & 16.0 & 16.0 & & 2. & & 0.15 \\
\hline 3 & 17.6 & 17.6 & & 2.6 & & 0.15 \\
\hline 4 & 20.0 & 20.0 & & 3.0 & & 0.15 \\
\hline 5 & 22.4 & 22.4 & & 3.3 & & 0.15 \\
\hline 7.5 & 28.0 & 28.0 & & 4.2 & & 0.15 \\
\hline 9 & 40.0 & 40.0 & & 6.0 & & 0.15 \\
\hline
\end{tabular}

For the unsupported slope, the deterministic and the probabilistic values of calculation and 1000 times of simulation are shown in Table 1.

The deterministic values of (F.S.) $)_{\text {mean }}$ and of (F.S. $)_{\mathrm{MLV}}$ are equal to 1.02 . The deterministic values for probability of failure for the first and second model are: $p(f)_{I}=45.5 \%$ and $p(f)_{I I}=43.3 \%$
Table 3: Comparison for the assumed data between the normal and lognormal distribution for the soil embankment

\begin{tabular}{lcll}
\hline & $\mathrm{T}=200 \mathrm{kN} \mathrm{m}^{-1}$ & $\mathrm{~T}=400 \mathrm{kN} \mathrm{m}^{-1}$ & $\mathrm{~T}=600 \mathrm{kN} \mathrm{m}^{-1}$ \\
\hline Normal distribution & & \\
$\beta_{\mathrm{N}}$ & -0.856 & 1.237 & 2.409 \\
$\mathrm{p}(\mathrm{f})$ & 0.804 & 0.108 & 0.008 \\
Lognormal distribution & & \\
$\beta_{\mathrm{LN}}$ & -0.842 & 1.200 & 2.748 \\
$\mathrm{p}(\mathrm{f})$ & 0.800 & 0.115 & 0.003 \\
\hline
\end{tabular}

For the simulation model (the third reliability model) shows the factor of safety having range from a minimum value of 0.66 to a maximum value of 1.45 and the simulated value of probability of failure for the third model, $[p(f)]_{\text {SIM }}=42.7 \%$. Default of repeat process is 1000 times.

Stabilization for the clayey soil foundation: Another example on the stability of foundation soil, which is the soft to stiff clay of embankment at the Suvarnabhumi (New Bangkok) international airport. This airport has been operated since September 26, 2006.

It is located in the southeast direction of Bangkok about $28 \mathrm{~km}$. An experimental embankment test was earlier done and the cross section of embankment is shown in Fig. 4. Their clay properties are indicated in Table 2.

The deterministic value of factor of safety for circular failure of embankment is Eq. 15:

F.S. $=\frac{M_{R}+M_{T}}{M_{Q}+\Delta M_{Q}}$

Term $M_{R}$ is the moment of capacity and $M_{T}$ is the stabilized moment. The term $\mathrm{M}_{\mathrm{Q}}$ is the demand moment and $\Delta \mathrm{M}_{\mathrm{Q}}$ is the additional disturbed moment Bergado et al. (1994).

The reinforcement technique using the synthetic geotextile is recommended. Each layer provides reinforced force of $200 \mathrm{kN} \mathrm{m}^{-1}$ per one layer. The deterministic value for one layer of geotextile, the F.S. is 0.939 . The two-layers will have better value of F.S. (1.096). The three-layers is suggested, the F.S. is 1.253 (Fig. 5).

In Table 3, the probabilistic calculation indicates that there are close relationships between the data of normal and lognormal distribution. The one layer of geotextile is not sufficient to support the saturated soil embankment. There should be at least 2 layers of reinforced geotextile, as earlier suggested by Bergado et al. (1994). If there is the tension crack occurred in the structure of embankment, to reinforce the embankment, only the three layers will be sufficient. 


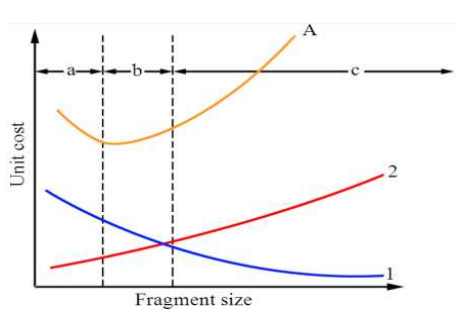

Fig. 6: The trial graphs during the optimization process on excavation using machinery or blasting. No. 1 is the direct excavation cost; No. 2 is other costs such as hauling and crushing. Term " $A$ " is the total cost of operation. Range "a" is the small block of fine size, range " $\mathrm{b}$ " is the medium block, the fragment size between 0.2 and $0.7 \mathrm{~m}$ and range "c" is the large block or fragment of over size.

\section{CONCLUSION}

Conclusions and recommendations: Implication on the use of reliability technique, it can explain in the simple way. A slope or foundation that has the safety value at F.S. $=1.0$ might fail. The local factor of safety may be more or less than the value of F.S. calculated by conventional limit equilibrium methods due to the variation of soil (rock) properties.

The reliability of cutting slope or foundation is the probability that the soil (or rock) mass will remain stable during the construction and beyond the end of construction for a life time period. The proposed models of reliability methods give various alternative steps in stability planning and evaluation. There are some options that the data simulation (the third reliability model) seems to perform better than the other reliability models. Back analysis calculations on the results of factor of safety, probability of failure, cost of excavation and impact factors to environment, are required. The trial graphs on the cost optimization, as shown in Fig. 6, could help to confirm the schematic plans represent efficient, economic and safe practices.

Further recommendations are based on the improvement of reliability models. These models should be performed on the other function distributions of random data and compare with the normal and lognormal function distribution suggested in this article. Observation in the field on the mass movement is also important, it can clarify the long term stability.

\section{REFERENCES}

Bergado, D.T., P.V. Long, C.H. Lee, K.H. Loke and G. Werner, 1994. Performance of reinforced embankment on soft Bangkok clay with highstrength geotextile reinforcement. Geotextiles Geomembranes, 13: 403-420. DOI: 10.1016/02661144(94)90005-1

Duncan, J.M., 2000. Factors of safety and reliability in geotechnical engineering. J. Geotechnical Geoenvironmental Engineering, ASCE, 126: 307-316.

Duncan, J.M. and S.G. Wright, 2005. Soil Strength and Slope Stability. 1st Edn., John Wiley and Sons, New Jersey, ISBN: 0471691631, p: 297.

Harr, M.E., 1987. Reliability-Based Design in Civil Engineering. 1st Edn., Dover Publications, Mineola, ISBN: 0486694291, p: 291.

Tangchawal, S., 2008. Statistical analyses on slope and foundation excavations: The reliability technique. Proceedings of the International Symposia on Geoscience Resources and Environments of Asian Terranes (GREAT 2008), 4th IGCP 516 and 5th APSEG, Nov. 24-26, Bangkok, Thailand, pp: 530533. ISSN: 1906-280x

Tangchawal, S., 2008b. Geotechnical Analysis. Chulalongkorn University Press, Bangkok, Thailand, ISBN: 9789740323693 p: 554. 